\title{
Ce que je sais de Vera Cándida: Tema y motivos del creador de Macondo ${ }^{1}$
}

\author{
Ce que je sais de Vera Cándida: Theme and \\ Motifs of the Creator of Macondo
}

\author{
Ce que je sais de Vera Candida: Tema e \\ motivos do criador de Macondo
}

Oscar Iván Arcos-Guerrero²

\section{Resumen}

Este artículo de reflexión parte de observaciones generales acerca de lo que la literatura comparada permite, en tanto disciplina enmarcada dentro de los estudios literarios. Enfatiza la necesidad de fomentar la comparación entre obras pertenecientes a nuestro continente con otras provenientes de regiones del mundo distintas a la nuestra. En este sentido, propone el análisis de los vínculos existentes entre Ce que je sais de Vera Candida de Véronique Ovaldé, La increíble y triste historia de la cándida Eréndira y de su abuela desalmada y Cien años de soledad. La novela francesa hace suyo el tema de la Cándida Eréndira, recreando para ello un espacio latinoamericano imaginario y valiéndose de algunos de los motivos presentes en la narrativa de García Márquez, por ejemplo, la melancolía, la soledad, las marcas de cruces en la frente y el incesto. Lo anterior permite vislumbrar no solo en qué obras del creador de Macondo ha focalizado su atención la autora al escribir su novela, sino también de qué forma las ha actualizado en el contexto literario francés mediante su ficción. El análisis que se propone se sustenta principalmente en la teoría de Luz Aurora Pimentel sobre la tematología y la transtextualidad. También, integra planteamientos de pensadores y analistas culturales que han reflexionado sobre los puntos en común encontrados entre García Márquez y Ovaldé.

\section{Palabras clave}

literatura comparada; tematología; literatura francesa contemporánea; literatura colombiana del siglo xx

\section{Abstract}

This reflection paper starts from general observations about what comparative literature allows as a discipline within literary studies. It emphasizes the need to promote the comparison between works from our continent and others from different regions around the world. In this sense, the paper proposes the analysis of the existing links between Ce que je sais de Vera Candida, by Véronique Ovaldé, La increíble y triste historia de la cándida Eréndira y de su abuela desalmada and Cien años de soledad. The French novel appropriates the subject of Cándida Eréndira, thus re-creating an imaginary Latin American space and using some of the reasons present in the narrative of García Márquez, such as melancholy, loneliness, the cross marks on the forehead, and incest. This makes it possible to see not only on which works by Macondo's creator the author focused her attention while writing her novel, but also how she has updated them in the French literary context through her own fiction. The analysis proposed is supported mainly in Luz Aurora Pimentel's theory of comparative thematics and transtextuality. It also includes the approaches of thinkers and cultural analysts who have reflected on the points in common found between García Márquez and Ovaldé.

Keywords

comparative literature; comparative thematics; contemporary french literature; 20th century colombian literature

1 El presente artículo constituye un adelanto de la tesis que su autor está desarrollando para optar por el título de magíster en Literaturas en Lenguas Extranjeras y en Literaturas Comparadas de la Universidad de Buenos Aires. Versiones preliminares, más reducidas y de carácter exploratorio, fueron presentadas ante el Grupo de Estudios de Cultura, Medios y Sociedad en América Latina, radicado en la casa de estudios mencionada (Arcos, 2015) y en las xxVIII Jornadas Nacionales de Literatura Francesa y Francófona (Arcos, 2016). El texto que aquí se presenta constituye una ampliación y reformulación de aquellos trabajos a partir de los comentarios y aportes que los pares académicos hicieron al autor en estos eventos.

2 Licenciado en Español y Lenguas Extranjeras por la Universidad Pedagógica Nacional de Colombia. Estudiante avanzado de la Maestría en Literaturas en Lenguas Extranjeras y en Literaturas Comparadas de la Universidad de Buenos Aires (Argentina). Docente del Departamento de Ciencias Jurídicas y Sociales de la Universidad Nacional de José C. Paz (Argentina). Correo electrónico: oguerrero@unpaz.edu.ar 


\section{Resumo}

Este artigo de reflexão parte de observações gerais sobre aquilo que a literatura comparada permite, como disciplina dentro dos estudos literários. Enfatiza-se a necessidade de fomentar a comparação entre obras pertencentes a nosso continente com outras de diversas regiões do mundo. Neste sentido, propõe-se a análise dos vínculos existentes entre Ce que je sais de Vera Candida de Véronique Ovaldé, A incrível e triste história da cândida Eréndira e da sua avó desalmada e Cem anos de solidão. 0 romance francês faz seu o tema da Cândida Eréndira, recriando para isso um espaço latinoamericano imaginário e com ajuda de alguns dos motivos presentes na narrativa de Gabriel García Márquez, como a melancolia, a solidão, as sinais de cruzes na testa e 0 incesto. Isso permite vislumbrar não só em que obras do criador de Macondo focalizou sua atenção a autora ao escrever seu romance, mas também de que forma as atualiza no contexto literário francês por meio da sua ficção. A análise proposta sustenta-se principalmente na teoría de Luz Aurora Pimentel sobre a tematologia e a transtextualidade. Também integra abordagens de pensadores a analistas culturais que já refletiram sobre os aspectos em comum encontrados entre García Márquez e Ovaldé.

\section{Palavras chave}

literatura comparada; tematologia; literatura francesa contemporânea; literatura colombiana do século xx

Artículo recibido el 13 de marzo de 2017 y aprobado el 28 de julio de 2017

Reflexionar sobre las circunstancias que marcan el tránsito de las producciones simbólicas de nuestro contexto cultural a otro no solo hace posible que nos situemos en el plano de lo nacional-regional, sino que además nos permite fijar nuestras coordenadas dentro del vasto mapa de lo transnacional; nos permite pensarnos como miembros de una comunidad cuyos orígenes, lengua y tradiciones son compartidos por sus integrantes, y además nos ayuda a analizar nuestro papel en las comunidades foráneas. En los estudios literarios, esto es posible gracias a la literatura comparada. Daniel-Henri Pageaux (1987), afirma que esta disciplina se presenta como una toma de conciencia producto del establecimiento de "una relación de un 'Yo' frente al 'Otro', de un 'Aquí' frente a un 'Allá”' (p. 97. Énfasis en el original)³. Sin embargo, como campo de conocimiento parece no haber sido lo suficientemente aprovechado por los latinoamericanistas y, por ende, tampoco sus posibles aportes. Salvo algunos casos aislados surgidos en la región, la literatura de América Latina se mantiene como un elemento difícil de abordar en los análisis que buscan estudiar su rol en los sistemas literarios transnacionales (Rincón, 1996; Sánchez-Prado, 2006) ${ }^{4}$.

3 En el cuerpo del artículo se consignan las referencias de los textos con el año de publicación de las ediciones consultadas. En la lista de referencias bibliográficas se incluye entre corchetes, solo cuando difiere de las versiones trabajadas, el año original de publicación de cada una de las fuentes.

4 Rincón es consciente de los debates académicos que sobre el objeto de estudio y el método de la literatura comparada se tejen en
De acuerdo con lo anterior, se hace necesario fomentar aquellos estudios en los que se cotejen producciones literarias de nuestro continente, con ficciones producidas en otras zonas del mundo con lenguas, costumbres y tradiciones que aunque forman parte de nuestro acervo cultural, tomadas en su individualidad, se tornan ajenas a las nuestras, como las de las naciones europeas. Este tipo de análisis contribuye a lograr una mejor autocomprensión de nuestras manifestaciones artísticas y a su vez permite un entendimiento de lo que para las comunidades del otro lado del Atlántico representa América Latina. Asimismo, favorece el aproximarse a otras literaturas distintas a las que se producen en lengua castellana y abordarlas desde aspectos inherentes a nuestras producciones estéticas. Al reflexionar sobre la noción de mapa y su importancia para la literatura latinoamericana de nuestro tiempo como estrategia de puesta en cuestión y de inversión de significado, Rincón (1996) afirma que son principalmente los trabajos de mujeres los que "entretejen de manera más expuesta las tensiones de género, clase, raza y etnia dentro de esta novísima experiencia cultural de conexiones, superposiciones y desplazamientos" (p. 91). La transformación de valores en torno a este tipo de problemáticas por parte de las autoras latinoamericanas se torna de este modo en un

las universidades y centros especializados. María Teresa Gramuglio (2006), por su parte, alude en un trabajo mucho más reciente al difícil marco dentro del cual se ubica la comparatística como campo de saber de los estudios literarios. 
rasgo distintivo de nuestras letras. Quizá sea este el punto en el que Véronique Ovaldé, escritora francesa contemporánea, tenga un primer nexo con las propuestas estéticas de nuestra región. Ella misma sostiene respecto de los lazos que la unen a esta región:

Leí mucha literatura de América Latina, también japonesa y anglosajona, pero me gustó mucho la pluralidad de la literatura latinoamericana. Leí a Roberto Bolaño [...] y la escritura latinoamericana en español. Todo lo que leí lo asimilé como parte de la identidad de ese mundo. Cuando quise contar la historia de esa generación de mujeres que buscaban traspasar algo a la próxima generación, ya no se trataba de un problema individual, de un momento de crisis en una sola persona. Todas mis novelas anteriores se trataban de eso. Ahora, con Vera Cándida, ya no. En esa empresa se volvió natural escuchar las voces de otros escritores, como García Márquez. (2014, p. 47).

No sorprende la observación de Ovaldé acerca de la diversidad de la literatura producida en América Latina; reflexiones similares habían sido formuladas ya hace más de quince años por teóricos como Pageaux (1987). En cambio, sí resulta particularmente llamativa su inclinación a leer autores de este continente y más aún la función que cumplió para su proyecto literario la lectura y apropiación del premio nobel colombiano. Es por este motivo que vale la pena analizar los vínculos literarios entre la narrativa de este escritor y Ce que je sais de Vera Candida (Ovaldé, 2014). En esta obra, catalogada por la crítica como una novela afín a la estética del boom latinoamericano y en particular al realismo mágico, su autora hace suyo el tema de la cándida Eréndira, recreando para ello un espacio latinoamericano imaginario y valiéndose de algunos de los motivos presentes en la narrativa del creador de Macondo, tales como la melancolía, la soledad, las marcas de cruces en la frente y el incesto. Lo anterior permite vislumbrar no solo en qué obras de García Márquez ha focalizado su atención al escribir su novela, sino también de qué forma las ha actualizado en el contexto literario francés mediante su ficción.

\section{Apropiación de tema y espacio}

Un primer acercamiento a la obra de Ovaldé que aquí nos ocupa le permite al lector hallar de inmediato un nexo con la narrativa del escritor de Cien años de soledad. El título, en cuanto paratexto (Genette, 1989), permite relacionar desde un primer instante Ce que je sais de Vera Candida con el universo ficcional del creador de Macondo, abriendo las puertas a una lectura de la novela a la luz de la producción narrativa de García Márquez. En este sentido, resulta significativa la edad de las protagonistas de La increíble y triste historia de la cándida Eréndira y de su abuela desalmada y la ficción francesa que analizamos, ya que permite asimismo poner de manifiesto los lazos de unión que se tejen entre ambas ficciones. En el caso de Ovaldé (2011), su protagonista tiene catorce años y vive con su abuela cuando su madre es hallada muerta en la selva: "Vera Candida avait quatorze ans et vivait depuis fort longtemps chez sa grand-mère quand Violette fut retrouvée morte dans la forêt, le visage déjà ruisselant de fourmis" (p. 79). Sin embargo, es también la edad en la que se da el contacto carnal funesto que llevará a engendrar a su hija. Lo anterior remite al relato de Eréndira, de quien se dice que cuando llega la desgracia a su casa "había cumplido apenas los catorce años, y era lánguida y de huesos tiernos, y demasiado mansa para su edad" (García Márquez, 2012, p. 141). Esta edad es el momento de su existencia en el cual, como en el caso de la novela francesa, inicia su vida sexual. Tal iniciación lleva en ambas historias a que haya un desplazamiento del personaje por los espacios ficcionales. Si en el caso de la cándida Eréndira la historia desemboca a partir de esta situación en una serie de sucesos vinculados con una prostitución que se ejerce de pueblo en pueblo del Caribe sudamericano a instancias de su abuela, en el caso de Vera Candida este acontecimiento la lleva a un embarazo que la obliga a trasladarse de su lugar de origen para evitar la ira de su abuela:

Quand il fut clair quelle ne pourrait plus cacher longtemps la nature de son état à sa grand-mère Rose Bustamante, Vera Candida décida de partir [...]. 
Il est d'ailleurs étonnant que Vera Candida se pensât assez coupable pour attirer les foudres de sa grand-mère Rose Bustamante, alors que celle -ci lui avait enseigné depuis toujours que les victimes sont des victimes, qu'elles ne sont jamais complices et que les salopards ne sont que des salopards. Comment avec de tels préceptes Vera Candida nosa-t-elle pas parler à sa grand-mère de cet engrossement? (Ovaldé, 2011, p. 85).

De acuerdo con lo anterior, Ovaldé hace suyo el personaje de García Márquez; lo vuelve pieza clave para la configuración del universo narrativo de su novela. Esta apropiación de la cándida Eréndira le permite a la autora francesa hacer suyo el tema propio del relato latinoamericano al cual pertenece, pues tal como Luz Aurora Pimentel (1993) afirma:

... el tema se asimila en el personaje [...] bajo la cobertura de un nombre propio, un tema-personaje es una síntesis de diversos motivos y de temas-valor, ordenados e interrelacionados de tal manera que dibujen un perfil narrativo que le confiera identidad al tema. (p. 221). [Énfasis en el original].

Desde esta perspectiva, con cada una de las versiones que se presenten del personaje (del temapersonaje) se lleva a cabo una actualización suya, lo cual lleva a que cada actualización se enfoque en un valor (un tema-valor). La carga temática reposará de distinta forma en cada actualización, y por ende tendrá una orientación ideológica diferente. En este sentido, el tema de la cándida Eréndira se renueva en la ficción francesa de Ovaldé con algunas variaciones. En la versión que de este personaje nos presenta la autora francesa hay un giro que permite hacer hincapié en el despertar sexual -triste, como el relato de García Márquez, según veremos más adelante-como forma de acceder a la madurez y al mundo moderno. El acto sexual desdichado es lo que hace que Vera Candida se movilice de su Vatapuna natal a un espacio mucho más cosmopolita como lo es Lahomeria:

Vera Candida n'avait jamais encore mis les pieds à Lahomeria ou sur le continent en général. Et ce fut un choc. Parce que ça navait rien à voir avec Vatapuna. Plus qu’une différence de lieu cétait l'impression d'avoir changé de siècle qui vous saisissait au sortir du bateau. Vera Candida navait jamais vu autant de voitures, de panneaux publicitaires [...], de boutiques, de femmes en minishort [...], il y avait aussi un bruit assourdissant, des haut-parleurs déversaient de la musique depuis les cimes des lampadaires sur les centaines de voitures qui filaient ou tentaient de filer sur le port. (Ovaldé, 2011, p. 91-92).

El llegar a Lahomeria produce en Vera Candida un impacto sin precedentes. Las maravillas de la ciudad moderna difieren de los elementos propios de su isla de origen, con los cuales se encontraba ya familiarizada. El ambiente urbano que constituye el nuevo sitio al que llega parece transportarla en el tiempo a un lugar colmado de artefactos novedosos que contribuyen a que sus habitantes lleven una vida sofisticada. Aparece ante sus ojos la ciudad moderna tal como lo hace en la obra de Baudelaire: un espacio colmado de gente, hormigueante y lleno de sueños (Benjamin, 2012b). La dinámica de la gran urbe, con su bullicio, sus multitudes y sus adelantos tecnológicos se muestra como un espacio nunca antes visto que le ofrecerá grandes posibilidades para salir adelante. Sin embargo, conviene focalizar nuestro interés en la isla de la cual procede la protagonista, puesto que es ahí donde los vínculos literarios con la obra de García Márquez resultan aún más evidentes para el análisis del universo ficcional propuesto por Ovaldé. Desde las primeras páginas es posible observar que la historia tiene sus inicios en Vatapuna, un lugar imaginario plasmado dentro de una atmósfera tropical en la que Vera Candida puede tener contacto con los aromas propios de tal ambiente:

Vera Candida pose son sac, elle respire lodeur des palétuviers, la poussière de la route, le gasoil, et les effluves du matin caraïbe - le ragoût et les beignets -, elle perçoit le jacassement des télés et des radios par les fenêtres ouvertes [...], le ressac de la mer en arrière-plan, un chuintement discret, elle reprend son sac et traverse le village, se dirige vers la cabane quelle a quittée vingt-quatre ans auparavant. (Ovaldé, 2011, p. 11).

Esto trae consigo reminiscencias del espacio ficcional dentro del cual se desarrolla la historia 
de La cándida Eréndira y de su abuela desalmada. Su narrador afirma haber conocido al personaje principal y a su abuela en los desiertos del Caribe, mientras desarrollaba sus actividades comerciales:

La conocí por esa época, que fue la de más grande esplendor [...]. Yo andaba vendiendo enciclopedias y libros de medicina por la provincia de Riohacha. Álvaro Cepeda Samudio, que andaba también por esos rumbos vendiendo máquinas de cerveza helada, me llevó en su camioneta por los pueblos del desierto con la intención de hablarme de no sé qué cosa, y hablamos tanto de nada y tomamos tanta cerveza que sin saber cuándo ni por dónde atravesamos el desierto entero y llegamos hasta la frontera. (García Márquez, 2012, p. 141).

En ambos textos, el Caribe se constituye en un espacio ficcional, un escenario propicio para cada una de las acciones que desarrollarán los personajes. En el caso de García Márquez, si bien se hace alusión a una región del norte de Colombia como Riohacha, la narración que presenta no posee un referente real, pues es el historiador el único que puede asegurar que su trabajo trata de "algo 'real', en el sentido de que aquello de lo que habla ha podido ser observado por los testigos del pasado. Diversamente, los personajes del novelista son simplemente 'irreales'; 'irreal' es también la experiencia que la ficción describe" (Ricoeur, 1996, p. 864. Énfasis en el original). Tal referente real es igualmente inexistente en el caso de Ovaldé. Aun cuando Vatapuna se constituye en un lugar imaginario situado en el norte de Suramérica, no hay ciudad o pueblo que lleve ese nombre. De esta manera, la autora hace suya América Latina, valiéndose de la realidad de nuestro continente y lo que de este se ha plasmado en la narrativa de sus escritores para crear el universo ficcional de Ce que je sais de Vera Candida. El espacio dentro del cual transcurre gran parte de la historia ${ }^{5}$ de esta novela se constituye

5 Ce que je sais de Vera Candida se desarrolla entre dos espacios: Vatapuna y Lahomeria. El primero de ellos se ve como una isla apartada del mundo, mientras que el segundo constituye un lugar continental: "Une ancienne camarade d'école lui avait dit que sa cousine habitait le continent et faisait des études de droit à Lahomeria. Vera Candida vint consulter un soir la camarade en question pour plus de renseignements [...]. La cousine, qui revenait une fois l'an à Vatapuna, avait apparemment adopté des mœurs fort así en un eco de Macondo, en la medida en que es un lugar irreal que solo existe en una ficción cuya geografía inexistente alberga un grupo familiar condenado, al igual que los Buendía, a la fatalidad de su destino, pues "las estirpes condenadas a cien años de soledad no tenían una segunda oportunidad sobre la tierra" (García Márquez, 2007, p. 471). El linaje femenino al que pertenece Vera Candida, constituido por ella, su abuela y su madre, también se encuentra marcado por la desgracia. No obstante, cuando la joven sale de la isla, la situación de su casta se modifica:

[Consuelo] continue à gueuler depuis son réduit:

Et puis de toute façon, ta grand-mère savait bien que tu attendais un petit quand tu t'es carapatée, doucette.

Vera Candida sent son estomac se nouer. La vieille poursuit:

Mais il était absolument nécessaire que tu t'en ailles d'ici pour rompre la fatalité. (Ovaldé, 2011, p. 290).

\section{Apropiación de motivos: melancolía y soledad}

El territorio de América Latina, junto con el personaje de la cándida Eréndira, es para Ovaldé objeto de apropiación. Sin embargo, es necesario ahondar en el análisis comparado que aquí se propone para establecer diferencias entre estas dos formas de hacer suya la literatura producida en tal zona. Desde la perspectiva de Pascale Casanova (2001), cada escritor se encuentra situado en el

\footnotetext{
libres et considérait que son appartement était, selon ses propres termes, 'une auberge espagnole" (Ovaldé, 2011, p. 86. Énfasis en el original).

Aunque no aparecen referencias directas a las ciudades europeas, el espacio de Lahomeria podría ser visto como una alegoría de la ciudad capital del viejo continente. Walter Benjamin (2012a) afirma que para la segunda mitad del siglo xIx, "París se confirma como capital del lujo y de las modas" (p. 53). Tal percepción concuerda con la que tiene Vera Candida al llegar a la gran ciudad. Con su llegada a Lahomeria, también es posible observar problemas relacionados con la migración, los cuales se presentan con mayor vehemencia en las urbes de los países más industrializados: “Vera Candida devait faire le voyage depuis Nuatu dans un chalutier qui remplissait ses cales d'anchois et d'émigrants clandestins" (Ovaldé, 2011, p. 91).
} 
espacio literario mundial tanto por el lugar que ocupa el espacio literario nacional del cual surge como por la forma en que lo hereda, al igual que por las elecciones que haga para definir su posición individual. Si al apropiarse de Eréndira para la configuración de su obra la autora francesa la actualiza, al igual que el tema que le es propio a este personaje, al apropiarse de América Latina como ambiente ficcional dentro del cual se ubica la Vatapuna imaginaria la autora se vale de motivos literarios que le permiten exhibir sus afinidades con la literatura de García Márquez y a la vez buscar en nuestra región una tradición literaria con la cual restituir la propia, reincorporándola como un pasado sólido para la elaboración de su obra y alejándose de la tradición artística y literaria escrita en lengua francesa. Por motivo literario entendemos, tal como lo hace Pimentel (1993), una unidad figurativa que constituye un bloque fijo, una forma narrativa autónoma que puede integrarse en conjuntos literarios más amplios, que se distingue del tema por su simplicidad y que aparece dentro de una narración "en forma de microrrelato o de figura" (p. 222). El Caribe, su inclusión dentro de la novela francesa, es una de las formas narrativas autónomas que le permite a Ovaldé establecer nexos con las producciones literarias del autor de Cien años de soledad y con los proyectos narrativos que este escritor ha desarrollado. Otros motivos comunes a los autores que nos ocupan son la melancolía y la soledad.

Para Freud (1992), la melancolía, como estado de ánimo, se vincula a un desasosiego fuertemente padecido, una falta de interés por el mundo exterior. Bajo su influjo, el ser humano pierde la capacidad de amar y muestra impedimentos para cualquier tipo de producción; le trae asimismo una reducción en el sentimiento de sí que se exterioriza en formas que van desde los reproches y las autodenigraciones hasta expectativas más altas de castigo. Desde esta perspectiva, es posible analizar la forma en que esta disposición anímica se hace presente en varios apartados de la novela de Ovaldé. Aparece a lo largo de Ce que je sais de Vera Candida junto con un sentimiento estrechamente vinculado a ella: la tristeza.
Una y otra constituyen para el texto un leitmotiv ${ }^{6}$ que lo atraviesa de comienzo a fin. En tanto motivo recurrente, está vinculado principalmente al linaje femenino del relato: se narra la forma en que Rose Bustamante se hunde en una melancolía completamente vatapuniana, cómo Violette se vuelve una terrible charlatana que multiplica las palabras tristes cuando crece, pese a haber sido tan silenciosa en su niñez, y cómo Vera Candida se siente presa de la melancolía y la apatía. Incluso se manifiesta en Monica Rose cuando abandona a su madre para siempre:

... elle ralentirait le pas au premier angle de rue, elle se sentirait malheureuse tout à coup, Monica, elle aurait presque couru pour l'atteindre ce premier angle de rue afin de disparaitre de la vue de sa mère qui, elle le devinerait, l'avait regardée séloigner derrière la vitre, elle se sentirait brutalement prise d'une envie de pleurer et d'un accablement infini. (Ovaldé, 2011, p. 269).

Sin embargo, aunque lo anterior se asocia a la protagonista principal de la historia y a su familia, también es posible evidenciar lo melancólico en otros personajes, como cuando se describen las acciones de Itxaga, compañero sentimental de Vera Candida mientras dura su estancia en la gran ciudad. De él se afirma que en su pasado fue un niño taciturno que amaba el fútbol, los cómics de Marvel y los libros de Agatha Christie. Su juventud tiene asimismo un carácter saturnino en el que la tristeza está ligada por momentos a otros sentimientos contrapuestos: luego de estar encerrado en su entrepiso durante mucho tiempo, recibe una llamada telefónica de Vera Candida, quien le pide que vaya hasta el número treinta de la Calle del Porvenir. Esto hace que su corazón se embargue tanto de entusiasmo como

6 Entendido como un motivo que se repite a lo largo de toda la obra y asume en ella un papel preciso (Todorov y Ducrot, 1974). Si bien los teóricos que nos brindan esta definición afirman en el texto fuente que se habla de tal término en literatura por analogía con la música, Anderson Imbert (1982) ahonda en la procedencia de este concepto. De acuerdo con él, leitmotiv proviene de la lengua alemana y habría sido empleado inicialmente para aludir a las óperas de Wagner: "era el motivo que, a fuerza de repeticiones, guiaba el desenvolvimiento de una melodía y se identificaba con personajes, emociones, y cosas. Al pasar al lenguaje de la crítica literaria [...] 'leitmotiv' conservó la nota de repetición" (p. 184. Énfasis en el original). 
de aflicción. Es en esta etapa de su vida cuando comienzan a vislumbrarse levemente los lazos de unión que atan a la melancolía con la contemplación. Al pasar por la cabina en la que Vera Candida y Monica Rose se habían tomado fotos y luego de tomar en sus manos los retratos instantáneos de ellas, Itxaga se siente tocado por un sentimiento de tristeza:

[Itxaga] saisit le miroitement du papier photo encore humide dans la petite cage où il était censé sécher. Il se pencha, sempara des photos, regarda en quadruple exemplaire les deux visages fixés sur le papier, il se sentit bizarrement et instantanément empli de gêne et de tristesse (mais les photos d'identité perdues ont peut-être toutes le pouvoir de nous rendre mélancoliques). (Ovaldé, 2011, p. 127).

No solo los personajes humanos que retrata Ovaldé aparecen vinculados a la melancolía. Esta se puede observar igualmente en los animales que suben al autobús que transporta a Vera Candida desde Vatapuna hasta Nuatu, en "[...] une bestiole dans une cage, une sorte de tout petit tamanoir qui couinait une longue lamentation" (p. 89). Incluso los espacios poseen también un vínculo con esta disposición emocional: el personaje de la novela piensa que el cuarto que habita mientras está en Lahomeria es "une sorte de volière pour oiseaux mélancoliques" (p. 121). No obstante, es en el linaje femenino de la protagonista y en su pareja en quienes irrumpe con mayor vehemencia. En este sentido, quizá el apartado más significativo en cuanto a su resonancia intertextual respecto de la narrativa de García Márquez es el correspondiente al capítulo "Convalescence muette d'Itxaga". El estado anímico de este último muestra aquí casi todos los síntomas del melancólico. Luego de haber sufrido los abusos cometidos por las autoridades de su ciudad, pasa sus días de recuperación sentado bajo un árbol, dedicando su tiempo a la contemplación en compañía de la propietaria del lugar donde vive:

Itxaga resta dans son entresol le temps de se remettre. Sa propriétaire [...] lui apportait du potage le soir et l'aidait à monter dans le jardin pour qu'il s'assît sous le sumac. Elle était charmante avec lui depuis qu'il était brisé. Ils restaient tous les deux ainsi sur le petit banc en plastique de la dame à regarder le coucher de soleil au-dessus du terrain vague, de l'autre côté du passage des Baleiniers. Ils ne se parlaient pas. Itxaga avait cent dix ans, il avait depuis longtemps pris sa retraite, jamais trouvé la femme de sa vie (ou plutôt il l'avait juste croisée un jour mais elle n'avait pas voulu de lui ou bien elle n'avait pas voulu la même chose que lui au même moment, ce qui est la clé de bien des échecs amoureux, pensait-il), il était maintenant immobile et tout abîmé [...], il espérait, dans une sorte de confuse béatitude, que ses dents et son petit doigt repousseraient un jour et il goûtait avec cette vieille dame des plaisirs silencieux et pétrifiés. (Ovaldé, 2011, p. 177).

$\mathrm{Al}$ analizar los vínculos entre acedía y melancolía a partir de las teorías formuladas por los pensadores de la Edad Media y el Renacimiento, Agamben (1982) afirma que es en la fuerte inclinación a la contemplación del carácter saturnino donde reaparece el Eros perverso del acidioso, quien habrá de mantener de forma invariable su propio deseo en lo inalcanzable. Esta tendencia a la abstracción, el apartarse del mundo para sumirse en la observación, es lo que permite que en Itxaga y en su casera se manifieste y perviva el deseo en las cosas inasequibles. Para el primero, lo inasible está dado por el amor: le ha sido imposible encontrar una mujer con la cual compartir su existencia. En el caso de la dueña del entrepiso, por el contrario, lo imposible se halla en la recuperación física y mental de su inquilino. Ahora bien, hay en esto una resonancia de la historia de Macondo, puesto que ante el ataque de ira de José Arcadio Buendía, que lo lleva a destrozar los aparatos de alquimia, el gabinete de daguerrotipia y el taller de orfebrería, este personaje es amarrado al castaño de la casa. Ya estando ahí, Úrsula, presa de su soledad, decide ir a verlo para que escuche sus quejas, pero su esposo se muestra sordo a estos lamentos e incluso ajeno a la realidad:

[Úrsula] Se sintió tan sola, que buscó la inútil compañía del marido olvidado bajo el castaño. "Mira en lo que hemos quedado", le decía, mientras las lluvias de junio amenazaban con derribar 
el cobertizo de palma. "Mira la casa vacía, nuestros hijos desperdigados por el mundo, y nosotros dos solos otra vez como al principio". José Arcadio Buendía, hundido en un abismo de inconsciencia, era sordo a sus lamentos [...]. Era como hablarle a un muerto, porque José Arcadio Buendía estaba ya fuera del alcance de toda preocupación [...]. Lo veía tan manso, tan indiferente a todo, que decidió soltarlo. Él ni siquiera se movió del banquito. Siguió expuesto al sol y a la lluvia, como si las sogas fueran innecesarias, porque un dominio superior a cualquier atadura visible lo mantenía amarrado al tronco del castaño. (García Márquez, 2007, p. 129).

La melancolía aparece así como un motivo común a García Márquez y a Ovaldé. El lector puede apreciarla en Cien años de soledad y también en Ce que je sais de Vera Candida ${ }^{7}$, encarnando la forma de dos personajes que se encuentran bajo un árbol sin lograr establecer mayor comunicación que aquella que les permite la proximidad de sus cuerpos. Tanto José Arcadio Buendía como Itxaga se muestran inmóviles y abismados. No obstante, al igual que con el tema de la cándida Eréndira, y más aún dado su carácter independiente, en este motivo también se presentan ciertas variaciones. Si el permanecer bajo el árbol se da en José Arcadio Buendía cuando los miembros de su familia deciden amarrarlo al tronco del castaño luego de haber perdido la razón, en Itxaga es posible gracias a la propietaria del departamento que habita, quien le ayuda a llegar desde su entrepiso a la sombra del zumaque en horas de la tarde. Esta variante en la función que cumple el género femenino en cada una de las obras se hace aún más evidente en la acción que lleva a que Úrsula y la casera de la obra francesa se encuentren con el patriarca de Macondo y con Itxaga, respectivamente: mientras en el caso de la novela latinoamericana la mujer busca consuelo en su marido, en la dueña del entrepiso de la novela de

7 La historia de la cándida Eréndira, por su parte, no es ajena al motivo de la tristeza. El lector puede evidenciarla tanto en el título del relato como en su interior, tratada de manera irónica para lograr efectos humorísticos en la escritura. Prueba de ello es el músico que acompaña a la protagonista de la narración y a su abuela, quien cobra más costosos los valses interpretados arguyendo que son canciones más tristes (García Márquez, 2012).
Ovaldé el afán por el consuelo es inexistente; solo la ata a su inquilino un sentimiento compartido que también une al primero de la estirpe ficcional latinoamericana con su esposa: la carencia de compañía con la cual hacer frente a las distintas adversidades del destino.

Es así como se hace presente otro sentimiento igualmente común a las obras que se analizan en este trabajo: la soledad. Tal como la tristeza, se hace presente en la novela ligado a la melancolía; atraviesa toda la obra, volviéndose también un motivo recurrente. Maurice Blanchot (2002) afirma al respecto que ser (en el mundo) apunta al hecho de significar que se es solo si se puede hallar una separación del ser: se niega el ser. En esta negación, los seres habrán de realizarse y los seres humanos habrán de levantarse en la libertad del "Yo soy"” (p. 223. Énfasis en el original). Sin embargo, esto solo es posible en la comunidad de todos. Hay en este planteamiento un atisbo de individualidad: el estar solo implica la división entre el yo y el ser, lo cual les permite a los individuos desarrollarse. Sin embargo, unas líneas más adelante, el mismo autor sostiene que esta posibilidad de desligarse del ser se transforma asimismo en separación de los seres. En este sentido, será la totalidad de un yo soy que quiere ratificarse sin los otros. Para que el yo pueda ser, tendrá que alejarse tanto del ser como de los seres. No obstante, la ausencia de estos dejará de tener connotaciones positivas para sí ante el mundo. De ahí que surja en el hombre el sentimiento de estar solo:

A esto se le llama generalmente soledad (a nivel del mundo) [...]. El Yo solitario se ve separado, pero ya no es capaz de reconocer en esa separación la condición de su poder, ya no es capaz de convertirla en medio de actividad y de trabajo, expresión y verdad que fundan toda comunicación exterior. (Blanchot, 2002, p. 224).

De acuerdo con lo anterior, revisamos los fragmentos de Ce que je sais de Vera Candida relacionados con la soledad. Esta aparece fundamentalmente con la protagonista en tres capítulos que marcan, de forma individual, un corte en la historia que se 
narra: en "Le retour de la femme jaguar", el cual narra el retorno a su lugar de origen; en "La montée des eaux", que cuenta su salida de Vatapuna siendo aún una adolescente y en "Ladieu à Itxaga", en el que se detalla tanto la forma en la que escribe una carta de despedida para su compañero como la manera en la que deja un último mensaje en la contestadora automática de su hija Monica Rose. Aparece asimismo en Rose Bustamante, de quien se afirma que después de haber escuchado la versión que Jeronimo le dio acerca del pasado de su cabaña, podía haber llorado ya que se sentía sola. Incluso parece ir más allá del linaje femenino para alcanzar a otros personajes. Así, será nuevamente Itxaga el que nos permita ejemplificar lo mencionado hasta el momento. Cuando se solicita su ayuda para denunciar un caso de violación ocurrido en la casa de inquilinato en la que vive Vera Candida, él se pregunta cuánto más podrá durar vivo si en sus trabajos como periodista continúa poniendo al descubierto acontecimientos que atentan contra la moral y que constituyen abusos e injusticias. Aunque esta duda le parece extraña en su momento, es consciente de que es producto de diversos sentimientos alojados en su interior, dentro de los cuales se encuentra la soledad, "l'infinie solitude étant la couche de crème acide qui ajutait à plusieurs reprises du moelleux à la chose" (Ovaldé, 2011, p. 191-192). Por otro lado, este sentimiento parece materializarse a través de él en los espacios ficcionales que frecuenta: Itxaga es encontrado por la policía estatal bebiendo cerveza en el Solitaire, un bar cercano a su casa en el que se debatía constantemente sobre peleas de gallos o de perros y donde había un billar. De esta forma, la sensación de estar alejado de los demás y del mundo se hace presente en su vida cotidiana; sin embargo, también aparece en otros momentos. Así como al final de sus días compartirá -como ya lo ilustramos- la ausencia de compañía con la dueña de su departamento, su infancia estará igualmente marcada por el aislamiento de sus semejantes:

Quand elle revînt à Lahomeria, la mère [d'Itxaga] était une toute jeune femme potentiellement riche et accompagnée d'un très beau petit garçon de quatre ans affligé d'une cicatrice à la lèvre (ce qui émouvait tout un chacun, lui octroyait un zozo- tement et l'empêchait de se faire des camarades de son âge, obstacle qui nétait finalement pas une si mauvaise chose pour son grand-père le préfet puisque celui-ci craignait fort l'influence du monde extérieur sur son jeune héritier) [...].

Hyeronimous Itxaga vécut avec sa mère dans un grand appartement bordélique de Lahomeria jusquà lâge de huit ans. Là elle disparut, ayant suivi on ne sait qui lors d'une soirée sans aube [...]. (Ovaldé, 2011, pp. 240- 241).

En cuanto motivo recurrente dentro de la ficción de Ovaldé, la soledad es un eco de ella misma presente en la novela de Macondo. En esta última, dicho sentimiento halla quizá su máxima expresión en el coronel Aureliano Buendía y en Úrsula Iguarán ${ }^{8}$; en la novela francesa se ve representado con vehemencia en Vera Candida y en Itxaga. Del primero de los personajes de García Márquez que acabamos de nombrar se narra cómo, luego de haber promovido y perdido treinta y dos levantamientos armados, de haber tenido con distintas mujeres diecisiete hijos que fueron exterminados en una sola noche $y$ después de haber sufrido los diferentes sinsabores que trae consigo un alto cargo militar en el oficio de la guerra, muere de viejo dedicado a la labor de fabricar pescaditos de oro. Su muerte llega luego de ver pasar el circo que arriba a su pueblo; fallece con la cabeza sobre el castaño y sin que el resto de su familia se entere sino hasta el día siguiente por los gallinazos que bajan hasta su cuerpo. De la mujer de

8 Esto no quiere decir que el resto de personajes que los acompañan carezcan de un destino solitario. Por el contrario, cada uno de ellos, de diversas formas y bajo múltiples perspectivas, otorga sentido al título de la novela. Recuérdese, por ejemplo, la muerte de Mauricio Babilonia, de quien se cuenta que muere siendo anciano "en la soledad, sin un quejido, sin una protesta, sin una sola tentativa de infidencia, atormentado por los recuerdos y por las mariposas amarillas que no le concedieron un instante de paz, y públicamente repudiado como ladrón de gallinas" (García Márquez, 2007, p. 332). Igualmente, piénsese en el personaje de José Arcadio Segundo y la vida que lleva luego de haber dejado de lado sus actividades sindicales. De él se afirma que se encierra en el cuarto de Melquíades: “Solo entonces comprendió Úrsula que él estaba en un mundo de tinieblas más impenetrable que el suyo, tan infranqueable y solitario como el del bisabuelo. Lo dejó en el cuarto, pero consiguió que no volvieran a poner el candado, que hicieran la limpieza todos los días, que tiraran las bacinillas a la basura y solo dejaran una, y que mantuvieran a José Arcadio Segundo tan limpio y presentable como estuvo el bisabuelo en su largo cautiverio bajo el castaño" (García Márquez, 2007, p. 382). 
José Arcadio Buendía, por el contrario, se cuenta que después de haber servido de sostén para su familia y tras haber sufrido los distintos altibajos por los cuales pasaron tanto ella como el pueblo de Macondo, se reduce físicamente hasta alcanzar un tamaño diminuto. En este estado, pierde la capacidad de ser escuchada y muere de vejez un Jueves Santo, enterrada en una caja que difícilmente sobrepasaba el tamaño de la cesta donde fue llevado Aureliano Babilonia. Muy poca gente asiste a su sepelio, puesto que nadie se acordaba de ella y porque además el calor del mediodía era sofocante.

Los personajes de García Márquez quedan de esta manera aislados de sus semejantes. $\mathrm{Al}$ respecto, Guillermo Pereyra (2010) afirma: "Para que haya soledad debe haber comunidad, pero la soledad también impide que haya (solo) comunidad" (p. 19). Esta relación entre elementos opuestos es la que se manifiesta en sus destinos. ¿De qué forma se observa esto en la ficción de Ovaldé? Volver sobre el personaje de Itxaga una vez más nos ayudará a resolver este interrogante. Toda su existencia ficcional, al igual que la de Vera Candida y su familia, se ve atravesada por el sentimiento de encontrarse siempre distante respecto del mundo que lo rodea. En la plenitud de su adultez, el estar solo es una sensación que él albergará internamente en su ser. En su niñez y en su vejez, sin embargo, el estar alejado del resto de la humanidad se manifiesta principalmente en el plano de lo físico, en la medida en que son pocas las personas que lo rodean en estos momentos. Su infancia presenta resonancias de la de Aureliano Babilonia, de quien se cuenta que es recibido y admitido en su casa por su abuela, pese a la voluntad contraria que manifestó ella durante toda su vida. Aislado inicialmente por Fernanda del Carpio en el taller del coronel Aureliano Buendía, es descubierto por Aureliano Segundo tres años después de su llegada a la casa de la familia de Macondo. Mientras le corta el pelo, lo viste y le enseña a perderle el miedo a la gente, su abuelo nota en su semblante que es un legítimo miembro de la familia, "con sus pómulos altos, su mirada de asombro y su aire solitario" (García Márquez, 2007, p. 360). Aureliano Segundo alberga la esperanza de que con el pasar del tiempo, su esposa permitirá a su nieto hacer una vida normal con los habitantes del pueblo. Sin embargo, Aureliano Babilonia muestra poco interés en el mundo exterior:

Aureliano Segundo confiaba en que la vejez ablandara el corazón de Fernanda, para que el niño pudiera incorporarse a la vida de un pueblo donde seguramente nadie se hubiera tomado el trabajo de hacer especulaciones suspicaces sobre su origen. Pero el propio Aureliano parecía preferir el encierro y la soledad, y no revelaba la menor malicia por conocer el mundo que empezaba en la puerta de la calle. (García Márquez, 2007, p. 395).

Aunque en cada una de las novelas la infancia aparece igualmente marcada por el sino de la soledad, en cada una de ellas adquiere matices distintos. Lo que en la novela de García Márquez aparece como el deseo de un abuelo de que su nieto haga una vida común con los miembros de su pueblo, en Ce que je sais de Vera Candida se transforma en el temor de la influencia del mundo exterior sobre el heredero. Estas diferencias se acentúan aún más si se tienen en cuenta las razones por las cuales cada uno de los chicos es aislado de sus semejantes. La novela latinoamericana nos muestra cómo Aureliano Babilonia es confinado a uno de los cuartos de la casa de la familia Buendía por iniciativa de su abuela, quien ve en él el retorno de una vergüenza ya exorcizada en el hogar. En la novela francesa, en cambio, el alejamiento de Itxaga respecto de sus semejantes se da a raíz de un defecto físico que le impide hablar correctamente y hacer amigos de su edad. Esta acción de la abuela, que hallamos solo en la obra colombiana, lleva a que resaltemos en cada una de las novelas la presencia de la mujer-madre ${ }^{9}$ en la vida de los personajes que aquí contraponemos, puesto que lo que es soledad por encierro en la novela del escritor colombiano se transforma en soledad por abandono en la de la escritora francesa. Tal como vimos en el fragmento citado, Itxaga vive con su mamá hasta los ocho años de edad. Aureliano Babilonia, por el contrario,

9 Desde la perspectiva de trabajo del autor del artículo, este término compuesto abarcaría no solo a la mujer que trae hijos al mundo sino también a la que cría, incluso, a aquellos que no han sido gestados en su vientre. 
convive en la misma casa con su abuela hasta el día en que ella muere.

\section{Las marcas de cruces en la frente $y$ el incesto}

Junto con los motivos literarios comunes a García Márquez y a Ovaldé que hemos analizado, dos más aparecen en las obras de estos autores. Merecen trabajarse de forma independiente a los anteriores debido al vínculo particular que tienen con ciertos personajes. En cuanto formas narrativas autónomas, se asociarán estrechamente solo con algunos de ellos. El primero es el de las marcas de cruces en la frente. En la historia de Macondo, los hijos que tuvo el coronel Aureliano Buendía y que diseminó en los territorios donde estuvo combatiendo llegan al pueblo atraídos por el ruido del jubileo de su padre. Antes de retornar a sus respectivos hogares en el litoral, reciben del padre Antonio Isabel la cruz de ceniza, que será una marca indeleble para ellos. Esa misma señal es la que posteriormente se constituirá en el blanco donde sus asesinos invisibles deberán disparar para matarlos. Es significativo el carácter anónimo que poseen quienes acaban con sus vidas y que años después, al terminar con la vida del último de ellos, se revelarán sin disimulos como pertenecientes a la fuerza pública. Mientras en el exterminio de los dieciséis Aurelianos asesinados a lo largo del litoral los responsables de cada asesinato permanecen sin identificarse, en la muerte del mayor de ellos, Aureliano Amador, los hombres que disparan sobre su cruz son agentes de policía que durante mucho tiempo han venido siguiéndole sus pasos:

Una calurosa madrugada [Aureliano Babilonia y José Arcadio] despertaron alarmados por unos golpes apremiantes en la puerta de la calle [...]. Era Aureliano Amador, el único sobreviviente de los diecisiete hijos del coronel Aureliano Buendía [...]. Se identificó, suplicó que le dieran refugio en aquella casa que en sus noches de paria había evocado como el último reducto de seguridad que le quedaba en la vida. Pero José Arcadio y Aureliano no lo recordaban [...]. Dos agentes de la policía que habían perseguido a Aureliano Amador durante años, que lo habían rastreado como perros por medio mundo, surgieron de entre los almendros de la acera opuesta y le hicieron dos tiros de máuser que le penetraron limpiamente por la cruz de ceniza. (García Márquez, 2007, p. 424).

Estas marcas reaparecen en la ficción de Ovaldé, pero adquieren otro carácter y otra función dentro de la diégesis. Siguiendo los planteamientos esbozados en la época clásica relacionados con el reconocimiento, es posible analizar el giro que la autora francesa da al respecto. Así como las cruces definen la fatalidad de los diecisiete aurelianos de la novela de Macondo, en Ce que je sais de Vera Candida permitirán trazar para madame Kaufman todo un pasado que la condenará en su vejez estando en Lahomeria. Así, es interesante observar cómo la autora juega con las formas de reconocimiento planteadas por Aristóteles (2011) para identificar a este personaje. De los cinco tipos que nos propone tal filósofo en su teoría, Ovaldé se vale inicialmente del reconocimiento por indicios. De esta forma, llama la atención del lector sobre la cuchara de Kaufman, hecha en plata y con un pequeño signo grabado en su mango. Este objeto es sustraído por Itxaga en la entrevista que tiene con ella, lo cual le permitirá publicar su artículo sobre el lugar que habita Vera Candida y la plata de la solución final. A raíz de esto, madame Kaufman se encierra en sus aposentos y luego desaparece de ahí sin dejar rastros. Aquí se da el paso del reconocimiento por indicios al que se da por la trama, puesto que con su desaparición, las madres solteras que ingresan a su departamento encuentran pruebas de un pasado oscuro, dentro de las cuales hallan un uniforme nazi. Sin embargo, esta última forma de identificación se hace aún más evidente cuando el narrador detalla la forma en que la Capa ${ }^{10}$ intenta vincular a Itxaga con la muerte de Kaufman:

Les types de la Capa avaient essayé pendant trois jours de lui mettre l'assassinat de la vieille Gudrun

10 Capa designa a un grupo policial que aparece en la novela francesa. Jugando con el significado de la sigla, su autora lo define como "Commission Anti-Protestation Armée; capacité de nuire à autrui; Catégorique et PAS commode" (Ovaldé, 2011, p. 143). 
Kaufman sur le dos et de lui faire signer des aveux [...]. La vieille Gudrun Kaufman qui avait été longtemps une amie personnelle du chef de la Capa (sous sa protection privée) et une indic précieuse avait fini par être un peu trop visible avec son passé qui scintillait dorénavant sur son front comme une croix gammée en paillettes. La faire assassiner par Itxaga était saugrenu mais efficace pour se débarrasser des deux à la fois.

(Ovaldé, 2011, p. 174).

Tanto los diecisiete Aurelianos como Madame Kaufman tienen un vínculo fatal con las fuerzas públicas del Estado. Mientras que en la novela de García Márquez la cruz deja de ser solo el símbolo del comienzo de la cuaresma para pasar a ser además el signo con el cual se imprime el destino mortal que ha de sufrir la descendencia del coronel Aureliano Buendía, en la novela de Ovaldé surge como el segundo término de una comparación que involucra el pasado de Kaufman. En este personaje, a diferencia de los diecisiete de la ficción latinoamericana marcados con el emblema cristiano, la cruz gamada remite a la simbología de un partido político cuya ideología posee connotaciones negativas para la humanidad. Mientras que en la historia de Macondo "La ceniza indeleble en la frente de los hijos del coronel atestigua sutilmente la complicidad de la iglesia en el exterminio de todo aquel que, eventualmente, pudiera conspirar en contra del orden establecido" (Araújo Fontalvo, 2016, p. 101), en Ce que je sais de Vera Candida la esvástica con la que se compara la vida secreta de Kaufman, que asoma sobre su rostro luego de su muerte, da cuenta de los encubrimientos de los adeptos al Nacionalsocialismo por parte de las fuerzas estatales. El símbolo de la Alemania de Hitler, configurado en su rostro mediante una figura literaria que lo equipara a sus vivencias de antaño, pone de manifiesto el tipo de relaciones turbias que la Policía, institución encargada de velar por el orden público y la seguridad de los ciudadanos, mantiene con sus colaboradores.

El segundo motivo es el incesto. Analizando las tribus autóctonas australianas, Freud (1991) observa el papel que estas le otorgan a la figura del tótem. Este tiene un carácter sagrado hereditario y brinda al individuo una pertenencia tribal que rebasa tanto los lazos de sangre como los adquiridos al compartir espacios comunes. Sin embargo, el sistema que con él se instaura no admite que miembros amparados bajo el mismo emblema entren en vínculos sexuales recíprocos, ni que se casen entre sí. Suzanne Jill Levine (1971), por su parte, afirma que este tipo de relaciones ha constituido durante muchos siglos uno de los tabús de la sociedad occidental, tanto por la restricción total que implica para algunas religiones como por el impedimento social que representa en comunidades primitivas y en las familias reales de Europa. Desde estas dos perspectivas, es posible observar en Cien años de soledad cómo sus personajes mantienen entre ellos lazos de unión prohibidos debido a que son miembros del mismo grupo familiar, transgrediendo así cualquier tipo de interdicción para su desenvolvimiento en el mundo ficcional. El sistema descrito y analizado por Freud se traslada al clan de los Buendía, grupo social instaurado en Macondo, para ser quebrantado; sus integrantes infringen tanto las normas de la naturaleza como las de la cultura ${ }^{11}$. De esta manera, las relaciones entre parientes constituyen el eje sobre el cual se desenvuelve la historia de la novela: comienzan con José Arcadio Buendía y Úrsula Iguarán, se desarrollan luego con su hijo José Arcadio y Rebeca, quien es hija adoptiva de los primeros ${ }^{12}$, prosiguen con Amaranta -quien mantiene primero lazos amorosos con su sobrino Aureliano José y luego

11 Lévi-Strauss (1969) afirma al respecto que en la prohibición del incesto la naturaleza se supera a sí misma. Desde su perspectiva, tal restricción en el plano de las relaciones humanas activa el mecanismo a través del cual "una estructura nueva y más compleja se forma y se superpone -integrándolas-a las estructuras más simples de la vida psíquica, así como estas últimas se superponen -integrándolas-a las estructuras más simples de la vida animal" (p. 59). Al incurrir en uniones carnales entre miembros de un mismo grupo, la familia Buendía impide que los sistemas interconectados mencionados en la anterior cita se desarrollen y superen los más básicos de la vida del hombre. Aunque con los vínculos entre sus personajes la novela sugerirá otra manera de organización cultural que transgrede la conocida y aceptada por las sociedades de 0ccidente, el cierre de la obra anuncia el fin de ese modelo.

12 Lo cual corrobora la idea de incesto que plantea Freud a partir del totemismo, según la cual aquel sobrepasa los vínculos de consanguinidad. En este sentido, al referirse al tipo de interacción entre los personajes de Cien años de soledad, Josefina Ludmer (1972) afirma que en la novela "hay incestos sociales, relaciones prohibidas entre las clases; hay imposibilidades geográficas" (p. 20). 
tratos eróticos con su sobrino nieto José Arcadio-, para llegar a su punto más alto con los actos carnales que llevan al nacimiento del último de los Buendía y al fin de la estirpe:

Aureliano sonrió, la levantó por la cintura con las dos manos, como una maceta de begonias, y la tiró bocarriba en la cama [...]. Amaranta Úrsula descuidó la defensa, y cuando trató de reaccionar, asustada de lo que ella misma había hecho posible, ya era demasiado tarde. Una conmoción descomunal la inmovilizó en su centro de gravedad, la sembró en su sitio, y su voluntad defensiva fue demolida por la ansiedad irresistible de descubrir qué eran los silbos anaranjados y los globos invisibles que la esperaban al otro lado de la muerte. Apenas tuvo tiempo de estirar la mano y buscar a ciegas la toalla, y meterse una mordaza entre los dientes, para que no se le salieran los chillidos de gata que ya le estaban desgarrando las entrañas. (García Márquez, 2007, p. 450).

Josefina Ludmer (1972) afirma que "un incesto abre la ficción y funda Macondo, el otro la cierra y destruye a Macondo; el primero se realiza entre un Buendía y una Iguarán, primos, el último entre una Buendía y un Babilonia, tía y sobrino" (p. 187. Énfasis en el original). Las relaciones entre miembros de la misma estirpe es una constante que atraviesa Cien años de soledad. Algunos de sus personajes, como José Arcadio Buendía y Úrsula Iguarán, tienen conocimiento del parentesco que los une, incluso antes de consumar el acto sexual entre sí. Otros, como Aureliano Babilonia, solo sabrán del vínculo familiar que los une a su pareja luego de terminar el acto carnal. Este tipo de relaciones también se hace presente en la obra de Ovaldé. Pese a que no es tan recurrente como en la novela de García Márquez, adquiere una significación particular por cuanto ayuda a configurar el sentido global de la ficción francesa. En esta se da una sola vez en la historia ${ }^{13}$,

13 Sin embargo, siguiendo la idea de Ludmer acerca de los nexos entre incesto y relaciones prohibidas, es posible evidenciar en la ficción de Ovaldé otros vínculos sexuales que transgreden las normas establecidas. Los lazos que unen a Violette con el hijo del alcalde de Vatapuna, por ejemplo, dan cuenta de una interdicción de tipo social que se transgrede. Con la violación de Lila por parte de Georges Martinez en el número 30 de la calle del Porvenir, por el contrario, en condiciones que implican una violación sexual que solo será revelada posteriormente: un incesto se anuncia en secreto ante los ojos del lector con la visita que le hace Vera Candida a Jeronimo para anunciarle la muerte de Violette, hija de él y madre de ella. Sin embargo, no será sino al final del libro cuando el lector descubra lo sucedido en ese encuentro:

La seule chose de vraie en définitive est que Jeronimo est à la fois l'arrière-grand-père et le père de Monica Rose, se dit Vera Candida [...]

Vera Candida, dans le dédale des couloirs détruits, réactive le dégoût quelle a de Jeronimo, faisant venir à elle les images de la journée qu’elle a passée chez lui dans la Villa quand elle était venue lui annoncer la mort de Violette, pensant, Ce connard imbibé n’a même pas compris qu'il avait affaire à sa petite-fille, continuant, Ce qui n'excuse rien, ajoutant, Nul ne lobligeait à me capturer comme une petite bête sauvage, à mattacher et me fourrer sa putain de bite dans la bouche jusqu'à me faire vomir, nul ne l'obligeait, c'est ainsi qu'on traite les fillettes?, ne l'obligeait à me violer avec sa putain de bite molle, et je me disais, Comment fera-t-il pour mettre ce truc en moi ? (Ovaldé, 2011, p. 305).

El incesto cumple en ambas ficciones un papel determinado cuya importancia es crucial para ellas. Con la relación carnal entre los últimos parientes de la historia de Macondo y en el desciframiento de los pergaminos de Melquíades, Aureliano Babilonia se muestra como una versión de Edipo que dedica su vida a la lectura de un solo texto que narra tanto su historia y su destino como el secreto de su propia identidad. Es el lector y por ende también es una figuración de nosotros: el público al que apela la ficción (Ludmer, 1972). En el caso del vínculo sexual entre Jeronimo y Vera Candida, por el contrario, el descubrimiento de su relación carnal al final del libro permite que el lector conozca los abusos

\footnotetext{
habría un quebrantamiento los códigos instaurados por la sociedad, por cuanto representa el acceso carnal violento de un mayor sobre una menor de edad. Dentro de las relaciones prohibidas se cuenta también la que entablan Rose Bustamante y Jeronimo, al igual que la de Itxaga y Vera Candida. En ambas, las mujeres interactúan con el que representa, respectivamente, su adversario.
} 
sexuales que sufrió la protagonista por parte de su abuelo meses antes de abandonar su lugar de origen y además devela quién es el padre de Monica Rose, hija de ella y bisnieta de aquel. Esto supone el descubrimiento de otro tipo de identidad: la del responsable de la violación de la que Vera Candida es víctima y, por ende, la del papá de su descendiente. En este sentido, si el sexo entre familiares implica en Cien años de soledad la realización del destino de la familia de Macondo que termina con la muerte del último de los Buendía y con la instauración de Aureliano Babilonia como el modelo de intérprete de la obra, en Ce que je sais de Vera Candida adquiere otro matiz, puesto que es lo que hace que se prolongue la estirpe de su personaje principal y a la vez funciona como pretexto literario para que el lector avance en la lectura de gran parte de la novela, abarcando el fragmento que va desde la salida de Vera Candida de Vatapuna a los quince años hasta su regreso a los treinta y nueve. Durante este tiempo, se cuentan los avatares que las mujeres de su casta han sufrido. Esto permite que con la revelación del vínculo carnal entre miembros del mismo linaje haya a su vez otro vínculo: el del incesto con la estructura novelesca ${ }^{14}$.

\section{Conclusión}

La apropiación y actualización del tema de la cándida Eréndira, junto con la forma de hacer suyos motivos ya presentes tanto en la novela corta de García Márquez publicada en 1972 como en Cien años de soledad, le ha permitido a Ovaldé configurar el universo ficcional de Ce que je sais de Vera Candida. En esta, su autora deja entrever la lectura de las obras del creador de Macondo que ella ha llevado a cabo y sobre las cuales ha focalizado su atención. El hacer suyos aspectos de la literatura del escritor colombiano lleva a que la autora cree una ficción propia y que al mismo tiempo renueve, en el siglo XXI, la obra de él en el marco literario francés. Tomados en su conjunto,

14 Este trabajo deja de lado el análisis de la apropiación de estructuras y de técnicas narrativas evidenciadas en la novela de Ovaldé. Se espera poder desarrollarlo en un artículo futuro, puesto que representa un aspecto ineludible al abordar los nexos entre los autores estudiados. le permiten narrar los distintos avatares que debe afrontar el género femenino por su condición en el mundo. Incluyendo rasgos distintivos de producciones literarias representativas de nuestro continente en una ficción cuyo principal cronotopo (Bajtin, 1989) permite evidenciar las formas de interacción de las mujeres con los hombres y con las estructuras socioculturales creadas por ellos, Ovaldé ha concebido una saga que ilustra los diferentes obstáculos que el segundo sexo debe sortear con frecuencia en un sistema de convenciones culturales basadas en el androcentrismo ${ }^{15}$. En todo esto radica la importancia de su análisis para los estudios literarios que se llevan a cabo en América Latina.

\section{Referencias}

Agamben, G. (1982 [1977]). Los fantasmas de Eros. Un ensayo sobre la melancolía. Revista de la Universidad de México, 11, 25-33.

Anderson Imbert, E. (1982 [1979]). Teoría y técnica del cuento. Buenos Aires: Marymar.

Araújo Fontalvo, O. (2016 [2010]). Gabriel García Márquez. El Caribe y los espejismos de la modernidad. Madrid: Verbum.

Arcos, O. (2015). Literatura francesa contemporánea y canon literario latinoamericano. (Comunicación inédita). Grupo de Estudios de Cultura, Medios y Sociedad en América Latina. Facultad de Ciencias Sociales de la Universidad de Buenos Aires.

Arcos, O. (2016). Ce que Je sais de Vera Candida de Véronique Ovaldé: Ecos del universo de Macondo en la literatura francesa contemporánea. En M. M. Borkosky y M. G. Castro (eds.). Metamorfosis y fronteras en la escritura francófona y cercanas (pp. 81-85). San Miguel de Tucumán: Facultad de Filosofía y Letras de la Universidad Nacional de Tucumán.

Aristóteles (2011). Poética. (E. Sinnot, trad.). Buenos Aires: Colihue.

Bajtin, M. (1989 [1975]). Teoría y estética de la novela. Madrid: Taurus.

15 Lo cual es algo importante si se tiene en cuenta la percepción que tiene la autora acerca de lo que acontece con las escritoras francesas. En su opinión, las mujeres en Francia publican tanto como los hombres, pero sus producciones se encuentran infravaloradas. Aparecen en reportajes sobre moda y vestuario, pero apartadas de lo que tiene relación directa con la creación literaria (Ovaldé, 2014). 
Benjamin, W. (2012a [1935]). París, capital del siglo XIX. En M. Dimópulos (trad.). El París de Baudelaire (pp. 43-63). Buenos Aires: Eterna Cadencia.

Benjamin, W. (2012b [1938]). El París del segundo imperio en Baudelaire. En M. Dimópulos (trad.). El París de Baudelaire (pp. 65-181). Buenos Aires: Eterna Cadencia.

Blanchot, M. (2002 [1955]). El espacio literario. Madrid: Editora Nacional.

Casanova, P. (2001 [1999]). La república mundial de las letras. Barcelona: Anagrama.

Ducrot, O. y Todorov, T. (1974 [1972]). Diccionario enciclopédico de las ciencias del lenguaje. Buenos Aires: Siglo XxI.

Freud, S. (1991 [1913]). Tótem y tabú. Algunas concordancias en la vida anímica de los salvajes y de los neuróticos. En J. L. Etcheverry (trad.). Obras completas: Sigmund Freud (vol. 13) (pp. 1-164). Buenos Aires: Amorrortu.

Freud, S. (1992 [1917]). Duelo y melancolía. En J. L. Etcheverry (trad.). Obras completas: Sigmund Freud (vol. 149) (pp. 235-258). Buenos Aires: Amorrortu.

García Márquez, G. (2007 [1967]). Cien años de soledad. Madrid: Alfaguara.

García Márquez, G. (2012 [1972]). La increíble y triste historia de la Cándida Eréndira y de su abuela desalmada. Buenos Aires: Debolsillo.

Genette, G. (1989 [1962]). Palimpsestos. La literatura en segundo grado. Madrid: Taurus.

Gramuglio, M. T. (2006). Tres problemas para el comparatismo. Orbis Tertius, 12, 1-15. Recuperado de http://www.memoria.fahce.unlp.edu.ar/art_revistas/ pr.202/pr.202.pdf.
Levine, S. J. (1971). La maldición del incesto en Cien años de soledad. Revista Iberoamericana, 76-77, 711-724.

Lévi-Straus, C. (1969 [1949]). Las estructuras elementales del parentesco. Buenos Aires: Paidós.

Ludmer, J. (1972). Cien años de soledad. Una interpretación. Buenos Aires: Tiempo Contemporáneo.

Ovaldé, V. (2011 [2009]). Ce que je sais de Vera Candida. Paris: Éditions J’ai lu.

Ovaldé, V. (2014). El realismo mágico en la creación literaria francesa de hoy. Conversación con Maurice Electorat. Dossier, 25, 43-47. Recuperado de: http:// www.revistadossier.cl/wp-content/uploads/numeros/UDP_Dossier_25_WEB.pdf

Pageaux, D. H. (1987). Hispanoamérica y literatura comparada. Annuario della Scuola Superiore di Lingue Moderne per Interpreti e Traduttori, 2, 84-98.

Pereyra, G. (2010). Sobre la soledad. En torno a una política imposible. Buenos Aires: Ediciones del Signo.

Pimentel, L. A. (1993). Tematología y transtextualidad. Nueva Revista de Filología Hispánica, 41(1), 215-230.

Ricoeur, P. (1996 [1985]). Tiempo y narración III. México: Siglo XXI.

Rincón, C. (1996). Mapas y pliegues. Ensayos de cartografía cultural y de lectura del neobarroco. Bogotá: Tercer Mundo.

Sánchez-Prado, I. M. (2006). "Hijos de Metapa”: un recorrido conceptual de la literatura mundial (a manera de introducción). En I. M. Sánchez-Prado (ed.). América Latina en la literatura mundial (pp. 7-46). Pittsburgh: Instituto Internacional de Literatura Iberoamericana. 